\title{
Evaluation of COVID-19 Pandemic Effects on the Quality of Education from the Perspective of Tabas Nursing School's Professors in Iran
}

\author{
Mostafa Abdollahi (iD ${ }^{1}$, Najmeh Tavakol (iD) ${ }^{2}$ and Ayoub Ayar (iD) ${ }^{1, *}$ \\ ${ }^{1}$ Department of Nursing, Tabas School of Nursing, Birjand University of Medical Science, Birjand, Iran \\ ${ }^{2}$ Poursina Hakim Digestive Diseases Research Center, Isfahan University of Medical Sciences, Isfahan, Iran \\ "Corresponding author: Department of Nursing, Tabas School of Nursing, Birjand University of Medical Science, Birjand, Iran. Tel: +98-5632822107, Email: \\ n90.a.ayar@gmail.com
}

Received 2021 October 20; Accepted 2021 December 05.

Keywords: E-learning, COVID-19, Quality of Education

\section{Dear editor,}

Coronavirus disease 2019 (COVID-19) is a respiratory disease known as the severe acute respiratory syndrome coronavirus 2 first identified in Wuhan, China (1). With the spread of the virus, the education system faced a completely unprecedented and great crisis. According to a United Nations Educational, Scientific and Cultural Organization report, more than $87 \%$ of students worldwide were affected by the disease, leading to the temporary shutdown of educational institutions (2). Colleges and educational institutions are struggling with a global education crisis caused by the COVID-19 pandemic, and the current situation has affected and transformed education methods and healthcare provision in numerous countries around the world (3). Most educational institutions, from primary schools to universities, are closed. Moreover, students have returned to their homes, sticking to quarantine and social distancing regulations (4). One month after the closure of universities in Iran, officials suggested the implementation of e-learning; accordingly, professors could upload educational materials for students (5). In a short period, millions of faculty members started teaching in front of a computer screen, and their students took the courses online at home (6).

Virtual learning has numerous advantages in comparison to traditional (face-to-face) educational programs, such as accessibility from anywhere and at any time, realtime discussions with classmates, instant feedback on tests, and flexible teaching. However, despite the benefits of virtual learning, it is not always easy to implement this strategy. Before the COVID-19 pandemic, the world faced a "learning crisis" (7). In traditional classroom education, the teacher's body language, facial expressions, and voice are all important teaching tools. When we switch to online education, the use of body language and facial expressions is limited. The disadvantages of e-learning include limited communication with the instructor, lack of interest in e-learning, lack of adequate support by the faculty, ineffective education during e-learning courses, inconsistencies between educational curricula and virtual courses, reduced competition between students, negative impacts on academic achievement, and students' personality development, deprivation of students from teachers' behavioral and practical attitudes, disregard for intellectual property rights, ethical issues, injustice, and inequality, lack of attention to the efforts of university personnel active in virtual learning, security threats for information and documents, slow Internet connection, lack of equipment, timeconsuming and costly review and feedback processes, student assignments, and lack of trust in virtual learning (8).

Virtual learning discussions are now trending in Iran, and e-learning has become one of the concerns of Iranian universities, highlighting the need for improving the quality of educational services. One essential step to upgrade the quality of education is to scrutinize the current quality of services. Low-quality education leads to the training of unqualified and scientifically unskilled human resources, compromising the country's economic, political, social, and cultural growth programs that rely on skilled human resources. This phenomenon, in turn, will challenge the role and credibility of the educational system's existence (9). Medical education, similar to higher education, needs to grow and change in parallel with the quality requirements of education. It is not merely important; it is vital for service-providing organizations, especially universities, to pay attention to quality. The importance of this 
issue is even more highlighted in medical universities due to the different nature of their services (10).

Findings show that before the onset of the COVID-19 pandemic, $82.6 \%$ of professors had no experience in virtual education, and $39.1 \%$ of professors used this method uncommonly. Furthermore, virtual education was often in a combined online-offline form in $82.6 \%$ of cases. The mean total score of education quality from the perspective of professors was $133.44 \pm 16.18$, and based on the Likert scale, it was 3.170 .38 , indicating an intermediate level (Table 1). An obligation to use virtual learning during the pandemic has caused serious challenges due to the persistence of the crisis, the relative preparedness of educational institutions in providing appropriate suitable educational environments, and professors' unfamiliarity with virtual learning methods. Over time, some professors succeeded in turning these threats into innovation opportunities and even upgrading the quality of education. It is necessary that each university specifically scrutinizes professors' challenges with and experiences of e-learning during the COVID-19 crisis; therefore, more efficient solutions are devised to address these problems in accordance with the virtual learning environment.

\section{Footnotes}

Authors' Contribution: M.A and A.A performed concept development, manuscript preparation, literature search, data collection, and language editing. N.T performed statistical analyses. All authors read and approved the final manuscript.

Conflict of Interests: The authors declare that there is no conflict of interest.

Ethical Approval: This study was approved by the Ethics
Committee of Birjand University of Medical Sciences, Birjand, Iran (code: Ir.bums.REC.1399.407).

Funding/Support: None was received by the authors.

\section{References}

1. Huang X, Wei F, Hu L, Wen L, Chen K. Epidemiology and Clinical Characteristics of COVID-19. Arch Iran Med. 2020;23(4):268-71. doi: 10.34172/aim.2020.09. [PubMed: 32271601].

2. d'Orville H. COVID-19 causes unprecedented educational disruption: Is there a road towards a new normal? Prospects (Paris). 2020:1-5 doi: 10.1007/s11125-020-09475-0. [PubMed: 32836420]. [PubMed Central: PMC7268589].

3. Al-Balas M, Al-Balas HI, Jaber HM, Obeidat K, Al-Balas H, Aborajooh EA, et al. Distance learning in clinical medical education amid COVID19 pandemic in Jordan: current situation, challenges, and perspectives. BMC Med Educ. 2020;20(1):341. doi: 10.1186/s12909-020-02257-4. [PubMed: 33008392]. [PubMed Central: PMC7530879].

4. Toquero CM. Challenges and Opportunities for Higher Education amid the COVID-19 Pandemic: The Philippine Context. Pedagogical Res. 2020;5(4). doi: 10.29333/pr/7947.

5. Afshari P, Abedi P, Eslami K, Rokhafrooz D, Maraghi E, Beheshtinasab $M$. The views of medical students about e-learning during pandemic of COVID-19 in Iran. ResearchSquare. 2020;Preprint. doi: 10.21203/rs.3.rs-47582/v1.

6. Bao W. COVID-19 and online teaching in higher education: A case study of Peking University. Hum Behav Emerg Technol. 2020;2(2):1135. doi: 10.1002/hbe2.191. [PubMed: 32510042]. [PubMed Central: PMC7262082].

7. Alves P, Miranda L, Morais C. The Influence of Virtual Learning Environments in Students' Performance. Universal Journal of Educational Research. 2017;5(3):517-27. doi:10.13189/ujer.2017.050325.

8. Keshavarzi MH, Soltani Arabshahi SK, Gharrahee B, Sohrabi Z, Mardani-Hamooleh M. Exploration of faculty members' perceptions about virtual education challenges in medical sciences: a qualitative study. J Adv Med Educ Prof. 2019;7(1):27-34. [PubMed: 30697546]. [PubMed Central: PMC6341450].

9. Esmaeili N, Golafshani A, Khavan M. [Effective Factors on Improving Educational Quality Management Approach in Medical Science Education]. Clin Exc. 2019;9(2):1-10. Persian.

10. Golafshani A, Salehi M, Zameni F. [Visionary Leadership Strategies for Quality of Health Higher Education]. Clin Exc. 2018;8(2):37-49. Persian. 
Table 1. Numerical Indicators of Education Quality from the Perspective of Professors of the Faculty of Nursing in Tabas, South Khorasan, Iran, During the Coronavirus Disease 2019 Pandemic Regarding Personal Characteristics and Their Relationship in 2020 - 2021

\begin{tabular}{|c|c|c|c|c|c|}
\hline Variables & No. & Mean \pm Standard Deviation & Median & Interquartile Range & Test Results \\
\hline Gender $^{a}$ & & & & & $P=0.776 ; Z=-0.323$ \\
\hline Male & 15 & $120.73 \pm 14.62$ & 118.00 & $(108.00,127.00)$ & \\
\hline Female & 8 & $120.75 \pm 15.72$ & 121.50 & $(109.50,131.00)$ & \\
\hline Scientific Ranking a & & & & & $P=0.971 ; Z=-0.075$ \\
\hline Instructor & 18 & $120.39 \pm 14.97$ & 120.00 & $(108.00,127.25)$ & \\
\hline Professor / Assistant Professor & 5 & $119.64 \pm 11.74$ & 116.00 & $(109.50,137.50)$ & \\
\hline Work Experience $(y)^{a}$ & & & & & $P=0.734 ; Z=-0.374$ \\
\hline Less than 5 years & 14 & $132.23 \pm 12.97$ & 116.50 & $(111.00,129.00)$ & \\
\hline 5 years and more & 9 & $122.44 \pm 18.99$ & 126.00 & $(104.50,135.00)$ & \\
\hline $\begin{array}{l}\text { To have e- learning before starting of the corona } \\
\text { pandemic }^{\text {a }}\end{array}$ & & & & & $\mathrm{P}=0.044 ; \mathrm{Z}=-2.030$ \\
\hline No & 19 & $118.11 \pm 14.32$ & 116.00 & $(108.00,127.00)$ & \\
\hline Yes & 4 & $133.25 \pm 9.50$ & 130.50 & $(126.00,143.25)$ & \\
\hline $\begin{array}{l}\text { The amount of use of e-learning before starting of the } \\
\text { corona pandemic }{ }^{b}\end{array}$ & & & & & $P=0.162 ; X^{2}=5.139$ \\
\hline nothing & 8 & $120.75 \pm 17.64$ & 117.50 & $(109.50,131.00)$ & \\
\hline little & 9 & $114.78 \pm 7.33$ & 112.00 & $(107.50,122.50)$ & \\
\hline A little & 5 & $126.40 \pm 15.77$ & 127.00 & $(113.50,139.00)$ & \\
\hline Type of e-learning during the Corona pandemic ${ }^{a}$ & & & & & $P=0.226 ; Z=-1.293$ \\
\hline Offline (recorded) & 3 & $125.67 \pm 3.21$ & 127.00 & $(122.00,128.00)$ & \\
\hline Simultaneous use of offline and online ones & 19 & $118.63 \pm 14.73$ & 116.00 & $(108.00,126.00)$ & \\
\hline How to e-learn in the corona pandemic ${ }^{b}$ & & & & & $\mathrm{P}=0.382 ; \mathrm{X}^{2}=1.925$ \\
\hline Adobe Connect & 17 & $121.24 \pm 16.38$ & 117.00 & $(109.50,133.50)$ & \\
\hline Social networks & 3 & $113.00 \pm 8.66$ & 108.00 & $(108.00,123.00)$ & \\
\hline Online virtual learning & 3 & $125.67 \pm 3.21$ & 127.00 & $(122.00,128.00)$ & \\
\hline I haven't had one & & & & & \\
\hline $\operatorname{Age}(y)^{c}$ & \multicolumn{5}{|c|}{$r=-0.151 ; P=0.491$} \\
\hline
\end{tabular}

${ }^{\mathrm{a}}$ Mann-Whiteny U.

${ }^{\mathrm{b}}$ Kruskal-Wallis.

${ }^{\mathrm{c}}$ Spearman correlation. 